\title{
Avaliação de genótipos de arroz sob efeito do ácido butírico
}

\author{
Mauricio Marini Kopp ${ }^{1,5}$, Viviane Kopp da Luz², Luciano Carlos da Maia², Jefferson Luiz Meirelles Coimbra ${ }^{3}$, \\ Rogério Oliveira de Sousa ${ }^{4}$, Fernando Irajá Félix de Carvalho² e Antonio Costa de Oliveira²
}

Recebido em 6/08/2007. Aceito em 20/04/2010

\begin{abstract}
RESUMO - (Avaliação de genótipos de arroz sob efeito do ácido butírico). Solos do tipo hidromórfico apresentam uma reduzida capacidade de drenagem, sendo utilizados principalmente para cultivo de arroz irrigado. Esta condição favorece o desenvolvimento de microrganismos anaeróbios que produzem substâncias fitotóxicas. O objetivo do trabalho foi avaliar a resposta de 25 genótipos de arroz ao ácido butírico, um composto produzido em solos de deficiente drenagem e alto teor de matéria orgânica. $\mathrm{O}$ trabalho foi executado em sistema de hidroponia com 4 doses do ácido e o delineamento utilizado foi blocos casualizados com 3 repetições em um esquema fatorial. As variáveis mensuradas foram comprimento de raízes (CR) e de parte aérea (CPA), número de raízes (NR) e matéria seca de raízes (MSR) e parte aérea (MSPA). Foram procedidas análise de variância, desempenho relativo e ajuste de regressões. Os efeitos para genótipos e doses de ácido butírico foram todos significativos. Apenas os efeitos de interação entre doses x genótipos para as variáveis CR e MSR revelaram significância. A variável CR foi a mais afetada pelo ácido e as regressões estabelecidas para essa variável revelaram 9 genótipos tolerantes e 16 sensíveis ao efeito fitototoxico do ácido butírico. Genótipos desenvolvidos para sistema de irrigação por inundação se mostraram mais tolerantes ao ácido. Palavras-chave: Estresse abiótico, ácidos orgânicos, Oryza sativa, fitotoxidez
\end{abstract}

\begin{abstract}
Rice genotype evaluation under butyric acid effect). Hydromorphic soils have low drainage capacity and are used mainly for growing irrigated rice.. This condition favors the development of anaerobic microorganisms that produce phytotoxic substances. The objective of this work was to evaluate the response of 25 rice genotypes to butyric acid, a phytotoxic compound produced in low-drainage soils with high organic matter content. This work was performed by hydroponics with four acid doses as treatments using a random block design with three replications. The variables measured were root (CR) and shoot (CPA) length, number of roots (NR) and root (MSR) and shoot (MSPA) dry matter. Analysis of variance, relative performance and regression fitting were performed. Significance for genotype and dose was found for all variables. Significance for the interaction (genotype vs. dose) was found only for CR and MSR. The variable CR was the most influenced by the acid and the regression established for these variables revealed nine tolerant and 16 sensitive genotypes. Genotypes developed for irrigated systems were more tolerant.
\end{abstract}

Key words: Abiotic stress, organic acids, Oryza sativa, phytotoxicity

\section{Introdução}

O arroz (Oryza sativa L.) é um dos três principais cereais em importância econômica e social a nível mundial. O Brasil é o principal produtor fora do continente asiático com 1,86\% da produção mundial, e o Rio Grande do Sul é responsável por aproximadamente $50 \%$ desta produção (Gomes \& Magalhães Jr 2004). Além destes fatores, o arroz é hoje estudado de maneira mais avançada devido a seu papel como genoma modelo para outras espécies (Devos \& Gale 2000; IRGSP 2005). O melhoramento genético desta espécie permitiu incremento significativo na sua produtividade, no entanto este incremento está apresentando ganhos cada vez mais lentos e dispendiosos. Assim, o estudo de caracteres de interesse como qualidade industrial do produto, resistência a pragas e moléstias (estresses bióticos), tolerância a frio, estiagens, encharcamento, toxidez por alumínio ou ácidos orgânicos (estresses abióticos), se torna fundamental para melhoria da eficiência de ganho genético da espécie (Janick 2007).

A ocorrência de solos do tipo hidromórfico em aproximadamente $20 \%$ da área total do estado do Rio Grande do Sul representa um fator extremamente prejudicial para o desenvolvimento da maioria das espécies cultivadas. A principal característica destes solos está relacionada à sua reduzida capacidade de drenagem natural o que faz com que o cultivo de arroz irrigado seja extremamente realizado nestes solos, pois o arroz é cultivado sob sistema de cultivo irrigado por inundação (Pinto et al. 2004). No entanto, com a manutenção de uma lâmina de água sobre o solo durante a maior parte do desenvolvimento da cultura, o $\mathrm{O}_{2}$ presente é consumido e os microorganismos anaeróbios passam a atuar causando fermentação da matéria orgânica (Ponnamperuma 1972). Este processo causa produção de elevada quantidade de produtos intermediários fitotóxicos, dentre os quais destacam-se os ácidos orgânicos alifáticos de baixo peso molecular (acético, propiônico e butírico), que ocorrem na faixa de concentração de 0,1 a $14 \mathrm{mM}$ (Gotoh \& Onikura 1971; Camargo et al. 1993; Angeles et al. 2006) e relação de 6:3:1 respectivamente (Bohnen et al. 2005). O ácido butírico apresenta elevado potencial de danos ao estabelecimento de plântulas de arroz, pois, apesar de estar em menor concentração na solução do solo, causa maior estresse, pois, quanto maior o tamanho da cadeia de carbonos do ácido maior é sua fitotoxidez (Rao \& Mikkelsen 1977a; Angeles et al. 2006). Kopp et al. (2007a) demonstraram que uma concentração de $10 \mathrm{mM}$ de cada ácido reduziu o crescimento radicular de arroz em torno de $44 \%$ com ácido acético, $70 \%$ com propiônico e $77 \%$ para o butírico, demonstrando a maior fitotoxidade do ácido butírico.

Os sistemas de semeadura direta e cultivo mínimo de arroz irrigado são muito utilizados, pois proporcionam aumento da produtividade e lucratividade associada à ele-

\footnotetext{
Embrapa Gado de Leite, Juiz de Fora, MG, Brasil

2 Universidade Federal de Pelotas, Faculdade de Agronomia Eliseu Maciel, Centro de Genômica e Fitomelhoramento, Pelotas, RS, Brasil

3 Universidade do Estado de Santa Catarina, Centro Agro-Veterinário, Departamento de Fitotecnia, Lages, SC, Brasil

4 Universidade Federal de Pelotas, Faculdade de Agronomia Eliseu Maciel, Departamento de Solos, Pelotas, RS, Brasil

5 Autor para correspondência: kopp@cnpgl.embrapa.br
} 
vada redução dos impactos ambientais advindos do cultivo convencional (Gomes \& Magalhães Jr 2004). Um de seus princípios fundamentais se refere a manutenção e em alguns caos até a adição de resíduos vegetais sob a superfície do solo, ocasionando maior produção de ácidos orgânicos de cadeia curta, que podem estar limitando o crescimento e a produtividade do arroz cultivado nesses sistemas (Johnson et al. 2006). Os efeitos relativos a presença destes ácidos orgânicos no solo são mais acentuados nas fases iniciais de desenvolvimento do arroz, ocorrendo menor germinação, menor crescimento radicular e menor peso e altura de plântulas (Sousa \& Bortolon 2002). Efeitos sobre outras fases de desenvolvimento como menor afilhamento, menor absorção de nutrientes e menor rendimento de grãos podem ser observadas quando as plantas estiverem submetidas a maior tempo de exposição ou concentrações mais severas destes ácidos (Camargo et al. 2001).

A seleção de genitores e a caracterização da variabilidade genética existente são decisivas para o incremento de eficiência em programas de melhoramento, pois uma das principais necessidades do melhorista é a identificação de plantas que possuam genes responsáveis por determinada característica de interesse (Brammer 2002) como tolerância a ácidos orgânicos. A caracterização de variabilidade genética têm sido desenvolvida em três ambientes: i) em condições de campo; ii) em casa de vegetação, sob condições semi-controladas e iii) em laboratório, com o uso de soluções nutritivas em condições ambientais controladas. Enquanto a avaliação de genótipos em ambientes artificiais não leva em consideração as reais pressões do meio, a seleção em ensaios de campo reúne grande número de variáveis não controladas, tais como tolerâncias diferenciais a estresses climáticos, bióticos ou nutricionais (Duncan \& Baligar 1990). No caso de gramíneas cultivadas, trabalhos mostram correlações significativas entre parâmetros obtidos em testes de campo e em ambientes artificiais, com solo ou solução nutritiva (Hawtin et al. 1996). Assim, uma maneira eficiente de avaliação de genótipos para tolerância a ácidos orgânicos em meio de cultivo pode ser realizada em sistemas de hidroponia sob condições controladas.

Kopp et al. (2007b) identificaram variabilidade genética para tolerância a ácidos orgânicos em aveia, no entanto para arroz ainda não existe descrita variabilidade passível de utilização pelos programas de melhoramento. A identificação de genótipos tolerantes a estresse abiótico se torna importante para estudos de variabilidade genética, função, regulação e ação gênica, devido às novas tecnologias (Sreenivasulu et al. 2007), além de serem utilizados na incorporação de genes em genótipos superiores por métodos de recombinação ou transformação (Kahl \& Lavi 2001). A incorporação de genes responsáveis pela tolerância aos ácidos orgânicos em genótipos de alta produtividade, poderá contribuir para o incremento da área cultivada no sistema de semeadura direta de arroz irrigado, e conseqüentemente, aumentar a produtividade, reduzindo os impactos ambientais do cultivo convencional e os custos de produção do cereal.
Os objetivos deste trabalho foram avaliar o desenvolvimento de plântulas de arroz submetidas à ação fitotóxica do ácido butírico, determinar a variável mais responsiva a fitotoxidez nas plântulas e identificar variabilidade fenotípica para o caráter tolerância ao ácido butírico em arroz.

\section{Material e métodos}

O trabalho foi realizado no Laboratório de Di-haplóides e Hidroponia do Centro de Genômica e Fitomelhoramento (CGF) da Faculdade de Agronomia Eliseu Maciel da Universidade Federal de Pelotas (UFPel), localizado no município de Pelotas - RS. Foram utilizados 25 genótipos de arroz os quais foram submetidos a 4 doses de ácido butírico. Os genótipos utilizados pertencem a coleção de trabalho do Banco de Germoplasma de Arroz do CGF/UFPel. Foram utilizados genótipos do grupo indica e japonica, e desenvolvidos para produção nos sistemas de cultivo irrigado e sequeiro (Tab. 1).

O experimento foi conduzido em sistema hidropônico onde foram utilizados potes com capacidade de 5,5 L nos quais foi adaptada uma tela de náilon a tampa de cada pote permitindo a sustentação das plântulas e o crescimento do sistema radicular para o meio de cultivo. Os potes permaneceram em tanque tipo "banho-maria" com temperatura de $25 \pm 1{ }^{\circ} \mathrm{C}$, com aeração da solução nutritiva para suprimento de oxigênio, permitindo o desenvolvimento do sistema radicular e iluminação artificial controlada (160 $\mu \mathrm{mol} \mathrm{m} \mathrm{m}^{-2} \mathrm{~s}^{-1}$, fotoperíodo de 14 horas).

A concentração da solução nutritiva utilizada foi: Nitrato de cálcio $\mathrm{Ca}\left(\mathrm{NO}_{3}\right)_{2} 4 \mathrm{mM}$, Sulfato de magnésio - $\mathrm{MgSO}_{4} 2 \mathrm{mM}$, Nitrato de potássio - $\mathrm{KNO}_{3} 4 \mathrm{mM}$, Sulfato de amônio - (NH4) ${ }_{2} \mathrm{SO}_{4}$ 0,435 mM, Fosfato de potássio monobásico - $\mathrm{KH}_{2} \mathrm{PO}_{4} 0,5 \mathrm{mM}$, Acido bórico - $\mathrm{H}_{3} \mathrm{BO}_{3} 10 \mu \mathrm{M}$, Molibdato de sódio - $\mathrm{NaMoO}_{4} 0,10 \mu \mathrm{M}$, Cloreto de sódio - $\mathrm{NaCl} 30 \mu \mathrm{M}$, Sulfato de zinco - $\mathrm{ZnSO}_{4} 0,8 \mu \mathrm{M}$, Sulfato de cobre - $\mathrm{CuSO}_{4} 0,3 \mu \mathrm{M}$, Sulfato de manganês - $\mathrm{MnSO}_{4} 2 \mathrm{mM}$, Ferro EDTA - FeSO $+\mathrm{Na}_{2}$ EDTA $10 \mu \mathrm{M}$ (Camargo \& Oliveira 1981).

Para constituição das parcelas experimentais, 160 sementes de cada genótipo foram desinfetadas com hipoclorito de sódio $10 \%$ e postas para germinação a $25 \pm 1{ }^{\circ} \mathrm{C}$ por 72 horas em papel filtro embebido em água, das quais foram selecionadas 120 com comprimento de raiz de $5 \mathrm{~mm}$ e uniformes para constituir o experimento. Os tratamentos foram constituídos por quatro concentrações de ácido butírico: 0 (controle); 2; 4 e 6 mM, e o $\mathrm{pH}$ foi ajustado para $4,7 \mathrm{com} \mathrm{HCl} 1 \mathrm{~N}$ ou $\mathrm{NaOH} 1 \mathrm{~N}$, e monitorado diariamente, pois segundo Rao \& Mikkelsen (1977b) o pH da solução nutritiva em experimentos com ácidos orgânicos é variável e interfere na toxicidade dos ácidos.

O delineamento experimental utilizado foi o de blocos casualizados, com três repetições num esquema fatorial, sendo que a unidade experimental consistiu de dez sementes para cada repetição. Após realização do sorteio, as unidades experimentais foram alocadas nas telas de náilon adaptadas às tampas dos recipientes de solução hidropônica contendo os tratamentos.

As plântulas permaneceram em solução nutritiva adicionada aos tratamentos por 14 dias. Após esse período elas foram retiradas da tela de náilon e avaliadas quanto aos seguintes caracteres: comprimento de raiz (CR) e parte aérea (CPA) em cm; número de raízes (NR); matéria seca de raízes (MSR) e de parte aérea (MSPA) em mg pesadas após secagem até peso constante em estufa com circulação de ar a $60^{\circ} \mathrm{C}$.

Os dados foram submetidos à análise de variância em um esquema fatorial considerando dose e genótipo como fatores fixos (Steel \& Torrie 1980). A seguir foi realizada uma análise de regressão linear simples da variável mais responsiva (Camargo \& Ferreira 1992), cálculo do desempenho relativo de cada variável avaliada, tomando como referência os resultados do tratamento na dose $0 \mathrm{mM}$ de ácido butírico (Parh et al. 2006) e uma análise de correlação simples de Pearson. Todas as análises foram realizadas com o software estatístico SAS (Statistical Analysis System 2002).

\section{Resultados e discussão}

Os resultados da análise de variância (Tab. 2) mostraram, pelo teste $\mathrm{F}$, efeitos significativos, a $5 \%$ de probabilidade de erro, para doses e genótipos em todas as variáveis. As 
Tabela 1. Denominação, subespécie e sistema característico de produção dos 25 genótipos de arroz avaliados em solução nutritiva com 4 concentrações do ácido butírico. Pelotas-RS, 2007.

\begin{tabular}{|c|c|c|c|}
\hline $\mathrm{N}^{\circ}$ & Genótipo & Subespécie & Sistema de Produção \\
\hline 1 & Tokiwa Nishiki & Japonica & Sequeiro \\
\hline 2 & Supremo & Indica & Irrigado \\
\hline 3 & Gohykuman Goku & Japonica & Sequeiro \\
\hline 4 & Nippombari & Japonica & Irrigado \\
\hline 5 & Texmont & Indica & Irrigado \\
\hline 6 & Toride 1 & Japonica & Irrigado \\
\hline 7 & Firmeza & Indica & Irrigado \\
\hline 8 & Pelota & Indica & Irrigado \\
\hline 9 & Caloro & Indica & Sequeiro \\
\hline 10 & CICA 8 & Indica & Irrigado \\
\hline 11 & Daw Dam & Japonica & Irrigado \\
\hline 12 & Taquari & Indica & Irrigado \\
\hline 13 & Rusip & Japonica & Irrigado \\
\hline 14 & IAS 12-9 Formoza & Indica & Sequeiro \\
\hline 15 & Yamada Nishiki & Japonica & Sequeiro \\
\hline 16 & Delmont & Indica & Irrigado \\
\hline 17 & $\mathrm{IAC}-47$ & Indica & Sequeiro \\
\hline 18 & Oryzica & Indica & Sequeiro \\
\hline 19 & Diamante & Japonica & Sequeiro \\
\hline 20 & Taipei & Japonica & Irrigado \\
\hline 21 & IPSL - 462 & Indica & Sequeiro \\
\hline 22 & Jaguarí - ESAV/IAMG - 19 & Indica & Sequeiro \\
\hline 23 & Bonança & Indica & Sequeiro \\
\hline 24 & Awini & Japonica & Irrigado \\
\hline 25 & Taim & Indica & Irrigado \\
\hline
\end{tabular}

Tabela 2. Resumo da análise de variância para as fontes de variação (F.V.) do modelo estatístico, graus de liberdade (G.L.); médias e coeficiente de variação (C.V.) das variáveis crescimento de raízes (CR) e parte aérea (CPA), número de raízes (NR), matéria seca de raiz (MSR) e de parte aérea (CPA) de 25 genótipos de arroz submetidos a quatro concentrações de ácido butírico. Pelotas-RS, 2007.

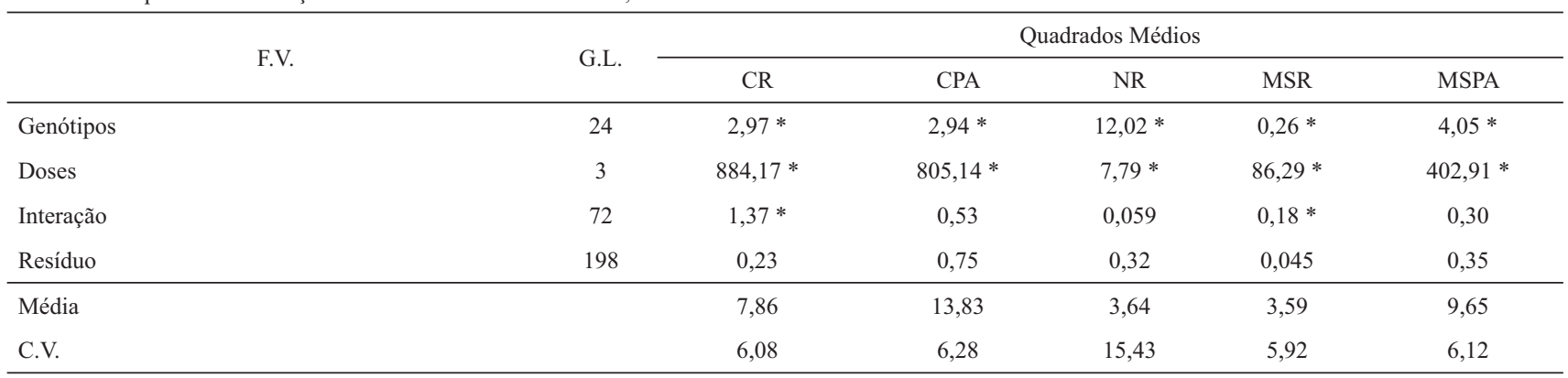

* Significativo a 5\% de probabilidade de erro pelo teste F.

interações (doses x genótipos) foram significativas apenas para as variáveis CR e MSR.

$\mathrm{Na}$ Tab. 3 são apresentadas as reduções relativas médias das variáveis CR, CPA, NR, MSR e MSPA, para cada dose. A maior redução relativa foi observada para a variável CR, demonstrando ser a mais sensível à toxicidade pelo ácido butírico. Estes resultados concordam com os obtidos por Rao \&
Mikkelsen (1977b); Camargo et al. 1993; Sousa \& Bortolon (2002); Kopp et al. (2007a) em arroz, que constataram que o comprimento de raiz é a variável mais afetada pelas doses com ácidos orgânicos. A matéria seca de raiz (MSR) também apresentou elevada redução nos valores com aumento das concentrações do ácido butírico. Armstrong \& Armstrong (2001) estudaram os sintomas fisiológicos relacionados à 
Tabela 3. Desempenho relativo (\%) das variáveis comprimento de raiz (CR) e parte aérea (CPA), número de raízes (NR) e matéria seca de raiz (MSR) e parte aérea (MSPA), de 25 genótipos de arroz submetidos a quatro concentrações de ácido butírico. Pelotas-RS, 2007.

\begin{tabular}{|c|c|c|c|}
\hline \multirow{2}{*}{ Variáveis } & \multicolumn{3}{|c|}{ Desempenho relativo (\%) * } \\
\hline & $2 \mathrm{mM}$ & $4 \mathrm{mM}$ & $6 \mathrm{mM}$ \\
\hline $\mathrm{CR}$ & 78,9 & 55,9 & 32,4 \\
\hline CPA & 84,6 & 73,0 & 56,0 \\
\hline NR & 99,1 & 103,1 & 119,0 \\
\hline MSR & 90,2 & 70,4 & 47,9 \\
\hline MSPA & 89,0 & 74,0 & 56,2 \\
\hline
\end{tabular}

* Reduções relativas tomando como referencial o valor absoluto no tratamento testemunha (dose $0 \mathrm{mM}$ ).

toxidez de ácidos orgânicos em arroz e relataram que eles causam degradação da parede celular, inibição das funções respiratórias e diminuição da divisão celular do sistema radicular que está em contato direto com o elemento tóxico, indicando assim, a razão principal para o menor crescimento e acúmulo de matéria seca na raiz.

Os resultados da avaliação do desempenho relativo, associados aos resultados da análise de variância permitem concluir que os genótipos apresentam respostas diferenciais em relação ao efeito do ácido, devido a suas interações significativas para as variáveis comprimento de raiz (CR) e matéria seca de raiz (MSR). Desta forma, devem ser ajustadas equações de regressão linear simples para cada genótipo individualmente, tomando como variável dependente (y) comprimento de raiz (CR) que foi o que se demonstrou mais responsiva a ação fitotóxica do ácido butírico, apresentando maiores índices de redução relativa (Tab. 3).

A análise da correlação simples de Pearson (Tab. 4), demonstrou que todas as variáveis analisadas apresentaram correlações significativas entre si. A variável NR apresentou correlação negativa com todas as outras variáveis analisadas, o que já era esperado segundo interpretação da Tab. 3, onde esta variável foi a única que sofreu acréscimos no seu desempenho relativo. Camargo et al. (2001) e Armstrong \& Armstrong (2001) observaram que as raízes adventícias diminuíam o seu crescimento, promovendo a proliferação de calos na base do coleóptilo, aumentando o número de raízes laterais, sendo esta a provável causa do aumento do número de raízes em arroz quando submetido a tratamentos com os ácidos acético, propiônico e butírico. Apesar destas correlações com a variável NR serem significativas, suas magnitudes são muito inferiores quando comparadas as demais correlações apresentadas. As demais variáveis apresentaram correlações positivas e significativas entre si, demonstrando terem o mesmo comportamento generalizado, ou seja, reduções nos valores médios de uma variável são acompanhadas de reduções similares nas demais variáveis correlacionadas no grupo dos 25 genótipos estudados. As magnitudes das correlações diferem das encontradas por Kopp et al. (2007a), no entanto estes autores utilizaram apenas dois genótipos, o que pode ter sido a causa das diferenças nas magnitudes das correlações encontradas no estudo.
As regressões estabelecidas em função da variável resposta CR podem ser visualizadas na Tab. 5. Os valores relativamente elevados obtidos para os coeficientes de determinação $\left(\mathrm{R}^{2}\right)$ permitem concluir que o modelo linear simples apresentou um bom ajuste em relação aos dados observados. As doses utilizadas para constituir os experimentos foram previamente selecionadas com base nos estudos de Rao \& Mikkelsen (1977b); Camargo et al. (1993); Sousa \& Bortolon (2002); Kopp et al. (2007a) de modo que as reduções relativas da variável comprimento de raiz (CR) utilizado para ajuste das equações fossem em torno de $50 \%$ na dose mais elevada (Tab. 3). No entanto, pode ser observado na Tab. 5, que os coeficientes de regressão (b) apresentaram valores com variação entre - 0,87 (genótipo Toride 1) a -1,56 (genótipo IAC-47). Esta amplitude de variação no decréscimo do valor de CR para os genótipos avaliados quando submetidos as doses com ácido butírico foi considerada significativa pelo teste $\mathrm{F}$ da interação genótipos $\mathrm{x}$ doses da análise de variância. No entanto, como ainda não existe na literatura a descrição de níveis de redução para considerar um genótipo tolerante, ou mesmo, não existem ainda descritos genótipos já classificados como tolerantes ou sensíveis para serem utilizados como testemunha, foi realizado um teste comparativo entre estes coeficientes de regressão.

Então, para avaliação da tolerância de cada genótipo, foi efetuado um teste $t$ do valor do coeficiente de regressão (b) de cada genótipo, onde, valores de coeficientes não significativos determinam genótipos tolerantes, ou seja, coeficientes significativamente iguais a zero. Segundo os resultados apresentados na Tab. 5, pode-se constatar que os genótipos Nippombari, Toride 1, CICA 8, Daw Dam, Rusip, Delmont, Oryzica, Taipei e Bonança foram os que apresentaram coeficientes de regressão não significativos para a variável comprimento de raiz quando submetidos a quatro níveis de ácido butírico, totalizando $36 \%$ de genótipos tolerantes ao ácido dentro do conjunto de genótipos utilizados neste estudo.

Na Fig. 1, as equações de regressão de dois genótipos com elevado contraste no índice de tolerância ao ácido (IAC-47 sensível e Toride 1 tolerante) foram representadas graficamente. Os resultados mostraram uma maior inclinação da reta representativa da regressão linear simples para o genótipo IAC-47 em relação ao Toride 1 demonstrando 
Tabela 4. Coeficientes de correlação de Pearson entre as variáveis comprimento de raiz (CR) e parte aérea (CPA), número de raízes (NR) e matéria seca de raiz (MSR) e parte aérea (MSPA), de 25 genótipos de arroz submetidos a quatro concentrações de ácido butírico. Pelotas-RS, 2007.

\begin{tabular}{|c|c|c|c|c|c|}
\hline & $\mathrm{CR}$ & $\mathrm{CPA}$ & NR & MSR & MSPA \\
\hline CR & & $0,914 *$ & $-0,140 *$ & $0,927^{*}$ & $0,912 *$ \\
\hline CPA & & & $-0,178^{*}$ & $0,896^{*}$ & $0,921 *$ \\
\hline NR & & & & $-0,199 *$ & $-0,182^{*}$ \\
\hline MSR & & & & & $0,889^{*}$ \\
\hline MSPA & & & & & \\
\hline
\end{tabular}

* Significativo a $5 \%$ de probabilidade de erro pelo teste $t$.

Tabela 5. Parâmetros das equações de regressão linear: interceptação no eixo y (a), coeficiente de regressão (b) e coeficiente de determinação ( $\mathrm{R}^{2}$ ) dos 25 genótipos de arroz estudados em solução nutritiva com quatro concentrações do ácido butírico para a variável comprimento de raiz (CR). Pelotas-RS, 2007.

\begin{tabular}{|c|c|c|c|c|c|c|}
\hline \multirow{2}{*}{ Genótipo } & \multicolumn{3}{|c|}{ Parâmetros de regressão } & \multicolumn{3}{|c|}{ Desempenho relativo $* *$} \\
\hline & $\mathrm{a}$ & $\mathrm{b}$ & $\mathrm{R}^{2}$ & $2 \mathrm{mM}$ & $4 \mathrm{mM}$ & $6 \mathrm{mM}$ \\
\hline 1 & 12,22 & $-1,41$ & 0,98 & 73,65 & 53,68 & 31,04 \\
\hline 2 & 11,97 & $-1,40$ & 0,87 & 72,35 & 52,16 & 31,29 \\
\hline 3 & 12,01 & $-1,38$ & 0,88 & 74,13 & 52,79 & 31,61 \\
\hline 4 & 11,63 & $-1,24^{*}$ & 0,91 & 84,07 & 57,08 & 36,39 \\
\hline 5 & 12,34 & $-1,54$ & 0,85 & 73,34 & 50,49 & 24,97 \\
\hline 6 & 11,47 & $-0,87^{*}$ & 0,90 & 97,81 & 79,15 & 52,23 \\
\hline 7 & 11,96 & $-1,49$ & 0,83 & 76,13 & 48,87 & 25,84 \\
\hline 8 & 12,48 & $-1,43$ & 0,91 & 76,02 & 52,84 & 31,94 \\
\hline 9 & 12,32 & $-1,52$ & 0,83 & 72,60 & 51,66 & 25,71 \\
\hline 10 & 11,56 & $-1,31^{*}$ & 0,84 & 83,82 & 57,60 & 30,97 \\
\hline 11 & 11,77 & $-0,98 *$ & 0,90 & 88,77 & 75,30 & 46,90 \\
\hline 12 & 11,94 & $-1,41$ & 0,89 & 80,30 & 52,96 & 28,99 \\
\hline 13 & 12,04 & $-1,07^{*}$ & 0,92 & 80,11 & 72,32 & 42,92 \\
\hline 14 & 12,20 & $-1,49$ & 0,98 & 80,75 & 49,25 & 27,69 \\
\hline 15 & 11,76 & $-1,45$ & 0,87 & 79,73 & 48,17 & 41,02 \\
\hline 16 & 11,59 & $-1,40^{*}$ & 0,84 & 90,26 & 50,61 & 28,14 \\
\hline 17 & 12,10 & $-1,56$ & 0,95 & 66,18 & 45,23 & 24,03 \\
\hline 18 & 11,36 & $-1,36^{*}$ & 0,88 & 89,56 & 50,50 & 29,06 \\
\hline 19 & 11,81 & $-1,36$ & 0,91 & 77,26 & 54,94 & 30,33 \\
\hline 20 & 11,65 & $-0,91 *$ & 0,96 & 96,31 & 78,39 & 50,52 \\
\hline 21 & 11,53 & $-1,42$ & 0,82 & 73,03 & 57,91 & 30,67 \\
\hline 22 & 11,63 & $-1,42$ & 0,88 & 74,27 & 49,94 & 27,11 \\
\hline 23 & 11,56 & $-1,35^{*}$ & 0,91 & 78,68 & 57,16 & 28,26 \\
\hline 24 & 11,18 & $-1,39$ & 0,87 & 79,98 & 50,95 & 32,55 \\
\hline 25 & 12,21 & $-1,51$ & 0,98 & 62,41 & 51,92 & 24,72 \\
\hline
\end{tabular}

*Não significativo pelo teste t a 5\% de probabilidade de erro para o modelo de regressão em 4 níveis de tratamento.

** Desempenho relativo tomando como referencial o valor absoluto no tratamento testemunha (dose $0 \mathrm{mM}$ ).

sua maior sensibilidade as concentrações do ácido. Pode ser constatado que apesar do genótipo IAC-47 apresentar um crescimento médio de raízes superior $(12,10 \mathrm{~cm})$ na ausência do ácido (dose 0), o acréscimo na concentração do ácido ocasionou um maior efeito sob a plântula, diminuindo consideravelmente seu desenvolvimento de raiz.
No caso do genótipo Toride 1, foi observado 11,47 cm de raiz na ausência do ácido (dose 0 ), e seu crescimento foi menos reduzido pelo aumento da concentração do ácido, resultando em um maior comprimento radicular na dose 6 $\mathrm{mM}$ em relação ao genótipo IAC-47, inicialmente superior em crescimento de raiz. 


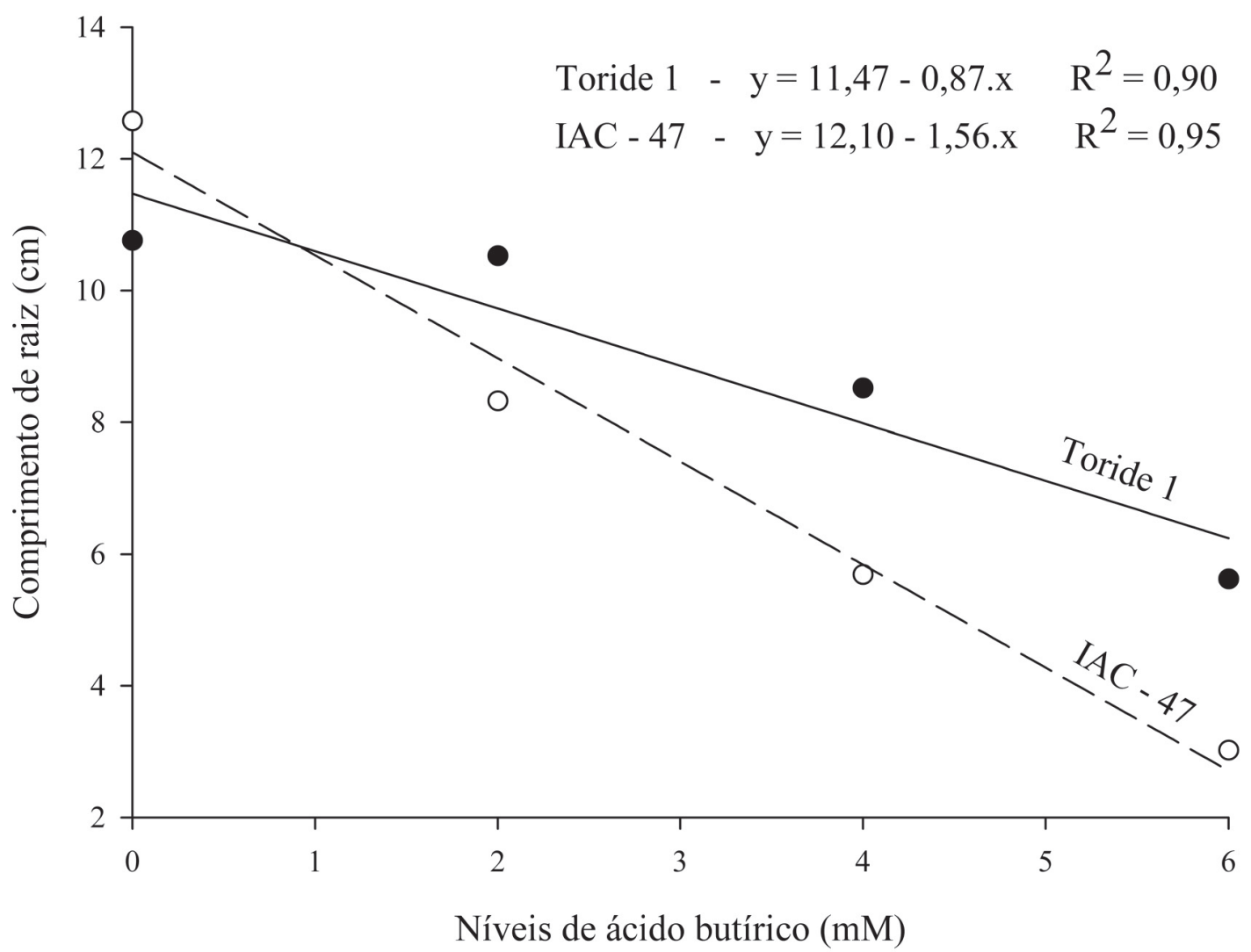

Figura 1. Efeito das concentrações do ácido butírico sobre o crescimento de raízes dos genótipos mais contrastantes em função de sua resposta ao estresse pelo ácido. Pelotas-RS, 2007.

Alguns genótipos como Delmont, Bonança e Oryzica, apesar de apresentarem desempenho relativo baixo, com valores inferiores a $30 \%$ na dose de $6 \mathrm{mM}$, foram classificadas como tolerantes, e outros como o Yamada Nishiki que apresentou desempenho relativo alto, com valor acima de $40 \%$, foi classificado como sensível (Tab.5). Isto pode ser explicado devido à inclusão do resíduo no teste $t$ dos valores dos coeficientes de regressão quando comparados contra o valor zero. A inclusão dos resíduos nas estimativas de parâmetros estatísticos é fundamental para que se obtenham os efeitos reais buscados pelos objetivos do experimento, minimizando desta forma os efeitos ambientais estimando de maneira mais eficiente os efeitos genéticos (Steel \& Torrie 1980).

Associando os resultados dos genótipos tolerantes e sensíveis (Tab. 5) com as descrições dos genótipos utilizados no estudo (Tab. 1) pode ser constatado que cinco dos nove genótipos que apresentaram tolerância ao ácido butírico pertencem ao grupo japonica. Assim, estes genótipos, podem ser utilizados pelos programas de melhoramento na forma de cruzamentos com genótipos de elevada produtividade e valor comercial. No entanto, o cruzamento entre estes dois grupos geralmente acarreta em recombinações insatisfatórias ao ideótipo focado nos programas de melhoramento de arroz no Brasil, principalmente no que diz respeito à qualidade de grãos. De forma mais clara, plantas do grupo japonica apresentam grãos curtos com baixos teores de amilose, tornando-os glutinosos durante o processo de cocção (Gomes \& Magalhães Jr 2004).

Outro fato que pode ser comprovado, é que apenas o genótipo Bonança dentre os genótipos tolerantes, não pertence ao sistema de cultivo de irrigação por inundação. Como o processo de melhoramento de genótipos sob sistema de inundação proporciona um ambiente com maiores concentrações de ácidos orgânicos (Camargo et al. 1993; Angeles et al. 2006; Bohnen et al. 2005), uma seleção indireta para o caráter pode ter sido decisiva para que um maior número de genótipos tolerantes fosse evidenciado dentro deste grupo. Armstrong \& Armstrong (2001) estudando o efeito dos ácidos orgânicos em arroz relataram que os ácidos causam principalmente degradação das membranas celulares e perda do conteúdo celular para o meio. Da mesma forma, Camargo et al. (1993) relataram que o efeito de ácidos orgânicos conduz a uma marcada redução do acúmulo vacuolar de solutos necessários ao influxo osmótico de água responsável pela manutenção da turgescência positiva das células. Assim, plantas tolerantes devem possuir genes que confiram maior capacidade de formação de membranas celulares que tolerem estes ácidos. 
A utilização dos genótipos tolerantes e sensíveis ao efeito fitotóxico do ácido butírico em programas de melhoramento, seja para estudos genéticos como mapeamento ou expressão gênica ou no melhoramento convencional através de cruzamentos e transferência gênica, poderão contribuir de maneira substancial no desenvolvimento de genótipos com maior percentual de germinação e estabelecimento inicial de plântulas na lavoura de arroz irrigado sob plantio direto ou cultivo mínimo. Isto reduziria significativamente os custos de produção e danos ambientais advindos do sistema de semeadura convencional de arroz, bem como aumentaria a produtividade final do cereal consideravelmente.

\section{Conclusões}

As variáveis comprimento de raiz e matéria seca de raiz, e as doses de 0;2; 4 e 6 mM de ácido butírico, são eficientes para estudo de caracterização de genótipos de arroz frente a fitotoxicidade por ácido butírico em sistema de hidroponia.

Foi constatada variabilidade fenotípica para o caráter tolerância ao ácido butírico nos genótipos de arroz utilizados com 36\% dos genótipos analisados tolerantes e $64 \%$ sensíveis. Os genótipos Nippombare, Toride 1, CICA 8, Daw Dam, Rusip, Delmont, Oryzica, Taipei e Bonança são tolerantes ao estresse por ácido butírico.

\section{Referências bibliográficas}

Angeles, O.R.; Johnson, S.E. \& Buresh, R.J. 2006. Soil solution sampling for organic acids in rice paddy soils. Soil Science Society of America Journal 70: 48-56.

Armstrong, J. \& Armstrong, W. 2001. Rice and Phragmites: effects of organic acids on growth, root permeability, and radial oxygen loss to the rhizosphere. American Journal of Botany 88: 1359-1370.

Bohnen, H.; Silva, L.S.; Macedo, V.R.M. \& Marcolin, E. 2005. Ácidos orgânicos na solução de um gleissolo sob diferentes sistemas de cultivo com arroz irrigado. Revista Brasileira de Ciência do Solo 29: $475-480$.

Brammer, S.P. 2002. Variabilidade e diversidade genética vegetal: requisito fundamental em um programa de melhoramento. Passo Fundo, Embrapa Trigo.

Camargo, C.E. de O. \& Oliveira, O.F. 1981. Tolerância de cultivares de trigo a diferentes níveis de alumínio em solução nutritiva e no solo. Bragantia 49: 21-23.

Camargo, C.E. de O. \& Ferreira, A.W.P. 1992. Tolerância de cultivares de trigo a diferentes níveis de manganês em solução nutritiva. Pesquisa Agropecuária Brasileira 27: 417-422.

Camargo, F.A.; Santos, G.A. \& Rossielo, R.O.P. 1993. Efeito dos ácidos acético e butírico sobre o crescimento de plântulas de arroz. Pesquisa Agropecuária Brasileira 28: 1011-1018.
Camargo, F.A.; Zonta, E.; Santos, G.A. \& Rossielo, R.O.P. 2001. Aspectos fisiológicos e caracterização de toxidez a ácidos orgânicos voláteis em plantas. Ciência Rural 31: 523-529.

Devos, K.M. \& Gale, M.D. 2000. Genome relationships: the grass model in current research. Plant Cell 12: 637-646.

Duncan, R.R. \& Baligar, V.C. 1990. Genetics, breeding, and physiological mechanisms of nutrient uptake and use efficiency: an overview. Pp.335. In: V.C. Baligar \& R.R. Duncan (eds.). Crops as enhancers of nutrient use. San Diego, Academic Press.

Gomes, A.S. \& Magalhães Jr., A.M. 2004. Arroz irrigado no sul do Brasil. Brasília, Embrapa-Informação Tecnológica.

Gotoh, S. \& Onikura, Y. 1971. Organic acids in a flooded soil receiving added rice straw and their effect on the growth of rice. Soil Science and Plant Nutrition 17: 1-8.

Hawtin, G.; Iwanaga, M. \& Hodgkin, T. 1996. Genetic resources in breeding for adaptation. Euphytica 92: 255-266.

International Rice Genome Sequencing Project. 2005. The map based sequence of the rice genome. Nature 436: 793-800.

JANICK, J. 2007. Plant breeding reviews. New Jersey, Wiley.

Johnson, S.E.; Angeles, O.R.; Brar, D.S. \& Buresh, R.J. 2006. Faster anaerobic decomposition of a brittle straw rice mutant: implications for residue management. Soil Biology \& Biochemistry 38:1880-1892.

Kahl, G. \& Lavi, U. 2001. Mutant germplasm characterisation using molecular markers. Viena, FAO-IAEA.

Kopp, M.M.; Luz, V.K.; Coimbra, J.L.M.; Sousa, R.O.; Carvalho, F.I.F. \& Oliveira, A.C. 2007a. Níveis críticos dos ácidos acético, propiônico e butírico para estudos de toxicidade em arroz em solução nutritiva. Acta Botanica Brasilica 21: 147-154.

Kopp, M.M.; Coimbra, J.L.M.; Luz, V.K.; Sousa, R.O.; Carvalho, F.I.F. \& Oliveira, A.C. 2007b. Organic acid tolerance in $M_{3}$ families of oat mutants. Crop Breeding and Applied Biotechnology 7: 59-66.

Parh, D.K.; Jordan, D.R.; Aitken, E.A.B.; Gogel, B.J.; McIntyre, C.L. \& Godwin, I.D. 2006. Genetic components of variance and the role of pollen traits in Sorghum ergot resistance Crop Science 46: 2387-2395.

Pinto, L.F.E.; Laus, J.A. \& Pauletto, E.A. 2004. Solos de várzea no sul do Brasil. Pp.75-95. In: A.S. Gomes \& A.M. Magalhães Jr. (eds.). Arroz irrigado no sul do Brasil. Brasília, Embrapa-Informação Tecnológica.

Ponnamperuma, F.M. 1972. The chemistry of submerged soils. Advances in Agronomy 24: 29-96.

Rao, D.N. \& Mikkelsen, D.S. 1977a. Effect of acetic, propionic, and butyric acids on young rice seedlings growth. Agronomy Journal 69: 923-928.

Rao, D.N. \& Mikkelsen, D.S. 1977b. Effects of acetic, propionic, and butyric acids on rice seedlings growth and nutrition. Plant Soil 47: 323-334.

Sousa, R.O. \& Bortolon, L. 2002. Crescimento radicular e da parte aérea do arroz (Oryza sativa L.) e absorção de nutrientes em solução nutritiva com diferentes concentrações de ácido acético. Revista Brasileira de Agrociência 8: 231-235.

Sreenivasulu, N.; Sopory, S.K. \& Kavi Kishor, P.B. 2007. Deciphering the regulatory mechanisms of abiotic stress tolerance in plants by genomic approaches. Gene 388: 1-13.

Statistical Analysis System 2002. SAS: Statistical Analysis System Getting Started with the $\mathbf{S A S}{ }^{\circledR}$ Learning Edition. Cary, NC, SAS Institute.

Steel, R.G.D. \& Torrie, J.H. 1980. Principles and procedures of statistics. 2.ed. New York, McGraw-Hill. 